\title{
A Relacion de la Vitoria que alcanzaron las Armas Catolicas en la Baia de Todos Santos, do Bispo D. Juan de Palafox y Mendoza
}

Pablo Antonio Iglesias Magalhães

\section{RESUMO}

O presente artigo investiga a impressão, em 1638, da Relacion de la Vitoria qve Alcanzaron las Armas Catolicas en la Baia de Todos Santos contra Holandeses, no contexto do projeto do Conde-Duque de Olivares de manter Portugal integrado à coroa de Castela, no período em que a União Ibérica apresentava significativos sinais de desgaste. Foi possível identificar em Dom Juan de Palafox y Mendoza o anônimo redator da referida relação e relacioná-la ao debate historiográfico em torno do Cerco da Bahia comandado pelo Conde João Maurício de Nassau-Siegen.

Palavras-chave: União Ibérica; Sítio da Bahia (1638); imprensa no período filipino.

\section{ABSTRACT}

This paper investigates the printing in 1638 of the Relacion de la Vitoria qve Alcanzaron las Armas Catolicas en la Baia de Todos Santos contra Holandeses in the context of the project of the Count-Duke of Olivares to keep Portugal integrated to the Castile's crown, in the period in which the Iberian Union demonstrated significant signs of wear. It was possible to identify Dom Juan de Palafox y Mendoza as the anonymous editor of that relation, and relate it to Bahia Siege - commanded by the Count João Mauricio de Nassau-Siegen historiographical debate.

Keywords: Iberian Union; Bahia Siege (1638); Philippine period Press. 
O sítio infligido a Salvador pela frota da Companhia das Índias Ocidentais, sob o comando do Conde Johann Mauritius van Nassau-Siegen, ou Maurício de Nassau, entre abril e maio de 1638, resultou na vitória das "forças católicas" de El Rey D. Felipe IV e causou comoção política na Espanha e em Portugal, então integrado aos domínios de Castela. A batalha pela conquista da capital da América portuguesa foi a primeira derrota dos neerlandeses no seu processo de conquista das capitanias do Brasil, iniciado em 1630 com a invasão de Pernambuco.

A historiografia do ataque de Nassau ao Recôncavo Baiano foi discutida em Episódios baianos: documentos para a história do periodo holandês na Bahia ${ }^{1}$, cuja edição inclui a publicação de três textos inéditos - particularmente do manuscrito da Relação Por Meio Breve e Verdadeira, atribuída ao senhor de engenho Henrique Moniz Telles -, resolvendo a questão das controvérsias que envolviam a organização do sistema defensivo da capital contra os neerlandeses em 1638. Para resumir essa discussão historiográfica, o livro Memorias Diarias de la Guerra del Brasil, escrito pelo Capitáo-donatário Duarte de Albuquerque Coelho, afirmava que o Conde de Bagnuoli e ele próprio foram os responsáveis por organizar a resistência e chefiar os dois contingentes militares da Bahia, além do Exército de Pernambuco, contra as forças de Nassau. A Relação de Manoel Fernandes de Figueiredo, médico de Bagnuoli, publicada também em Episódios baianos, se alinha à narrativa apresentada nas Memorias Diarias.

Antônio Xavier da Gama Pereira Coutinho, na tese publicada em 1937, reivindica para os portugueses a iniciativa da defesa e da vitória contra o assédio neerlandês à Bahia. Baseado na incapacidade estratégica de Bagnuoli, demonstrada no fracasso da Guerra de Pernambuco, argumenta que não foi o militar napolitano quem estimulou a luta e, sim, os moradores da cidade, por iniciativa de João Álvares da Fonseca Coutinho, vereador mais antigo da Câmara da Bahia, ascendente do autor. Em favor dessa tese, publica 14 certidóes passadas por autoridades da Bahia, nas quais se enaltece os serviços de Fonseca Coutinho².

Outro texto essencial para compreender os detalhes da tentativa neerlandesa de conquistar Salvador é a Relação Diária do Cerco da Baía, conjunto de cartas do provedor-mor Pedro Cadena de Vilhasanti, publicado por Manuel Múrias em 1941. Contudo, o mais importante documento sobre o Cerco de 1638 é a Relaçáo Por Meio Breve e Verdadeira, de Moniz Telles, cujo manuscrito original está conservado na Biblioteca Nacional de Portugal. Nela, o autor opóe-se a Duarte Coelho e a Fernandes de Figueiredo, na medida em que afirma que as autoridades militares, dispostas a abandonar as defesas da capital na iminência do ataque nassoviano, foram pressionadas pelo povo para se manter em seus postos e enfrentar os invasores neerlandeses. Assim, a iniciativa da defesa de Salvador e do Recôncavo Baiano, em 1638, coube aos seus moradores que obrigaram os militares a permanecer na cidade, tomaram armas, participaram dos combates e deram a assistência logística que sustentou os quarenta dias de cerco.

Apesar da questão historiográfica acerca da organização da defesa de Salvador ter sido examinada, nota-se que o referido conjunto de textos sobre os quarenta dias do ataque ao Recôncavo, ainda que circulassem manuscritos à época, só foram publicados muito posteriormente. Em meio a esse conjunto de manuscritos, há duas relaçóes que foram impressas na Espanha, ainda em 1638. Uma tornou-se o relato oficial do episódio.

Fernando Bouza Álvares chama a atenção para a valorização das correspondências epistolares, trocadas entre diferentes personagens, e das relaçôes de fatos que noticiavam ações políticas, movimentos militares e eventos curiosos, dentro e fora do próprio reino. Essas correspondências e relaçóes eram copiadas muitas vezes para serem difundidas, alcançando grande número de leitores. Bouza Álvares ainda atenta para o volumoso repertório de "relaciones de sucesos", impressas desde o século XVI, que também circulavam manuscritas, que "ejemplifica muy bien la doble circulación de noticias que en momento alguno se anulan entre si, sino que se refuerzan mutuamente" ${ }^{3}$.

Francisco José Aranda Pérez e José Damião Rodrigues, em De Re Publica Hispaniae, afirmam que é muito frutífero aprofundar os estudos acerca dos veículos de transmissão da cultura política ibérica, 
tanto em sua própria materialidade, como nos gêneros e modismos utilizados, não só na forma, senão no conteúdo mesmo da mensagem política. Assim, a gama de possibilidades de estudos é ampla e podese investigar, desde os elementos formadores de uma obra (índice, fontes, tábuas e anexos), até os objetivos de periódicos, avisos, panfletos e relaçôes ${ }^{4}$. Esses historiadores chamam a atenção para que, em "todas estas versiones de escritos de naturaleza política hay que permanecer atento a la dialéctica impresosmanuscritos y tratar siempre de comprender por qué algunos de estos artefactos se imprimen mientras que otros circulan o corren manufacturados"s.

É essa "dialética impressos-manuscritos" que buscamos investigar em relação ao episódio do Cerco da Bahia em 1638; ou seja, entender porque alguns textos que o noticiaram foram impressos, enquanto outros circularam manuscritos pela Península Ibérica. O livro de Duarte de Albuquerque somente foi impresso em Madri em 1654, vinte e seis anos depois da batalha por Salvador. O conjunto epistolar de Pedro Cadena Vilhasanti foi publicado, apenas, em 1941, e as já mencionadas relaçóes Por Meio Breve e Verdadeira e a do médico Fernandes de Figueiredo, em 2010. Por que essas relaçóes de origem portuguesa não foram impressas à época da vitória sobre a Companhia das Índias em maio de 1638, acontecimento tấo significativo para a hegemonia luso-espanhola no Atlântico Sul?

A primeira resposta é que, apesar da reconhecida importância da circulação dos manuscritos na Península Ibérica, a publicação por meio da imprensa revestia as notícias de um caráter oficial. Era necessário, inclusive, para a sua impressão, as licenças do Desembargo, do Ordinário, do Santo Ofício e, no caso de clérigos regulares, de alguma autoridade superior da ordem ou congregaçáo. Essa censura prévia implicava que qualquer crítica ao governo ou à Igreja resultava na proibição de publicação.

A segunda resposta está na política do Conde-Duque de Olivares, para Portugal, nos anos de 1630. Ao contrário do que ocorreu na perda e reconquista de Salvador em 1624 e 1625, quando em Portugal foram impressos diversos relatos contando os feitos das armas portuguesas na recuperação da Bahia, nenhuma relação sobre o triunfo contra Nassau em 1638 foi impressa em território português. A circulação de manuscritos portugueses sobre o episódio confirma, não obstante, a comoção causada entre os lusitanos pela vitória contra os neerlandeses que originou considerável número de relatos, informes e correspondências que descrevem os quarenta dias de sítio.

Em meio a esse conjunto de manuscritos sobre o Cerco de 1638, surgem as duas relaçóes impressas na Espanha; uma de caráter oficial, visto ter sido impressa com licença do Real Conselho de Castela e ajustada com o Conselho de Portugal. Qual a razão deste silêncio em Portugal em contrapartida às impressões espanholas? A resposta está nos objetivos políticos da monarquia filipina, que Jean-Frédéric Schaub definiu como "visages quotidiens de l'unión de armas".

Desses dois impressos espanhóis, a publicação mais importante foi, sem dúvida, a Relacion de la Vitoria que alcanzaron las Armas Catolicas en la Baia de Todos Santos, contra Olandeses, que fueron a sitiar aquella Plaça, en 14. de Iunio [sic] de 1638. Siendo Gouernador del Estado del Brasil Pedro de Silua. Impressa con licencia del Real Consejo de Castilla, y conferida y ajustada en el Supremo de Estado de Portugal (Figura 1). 


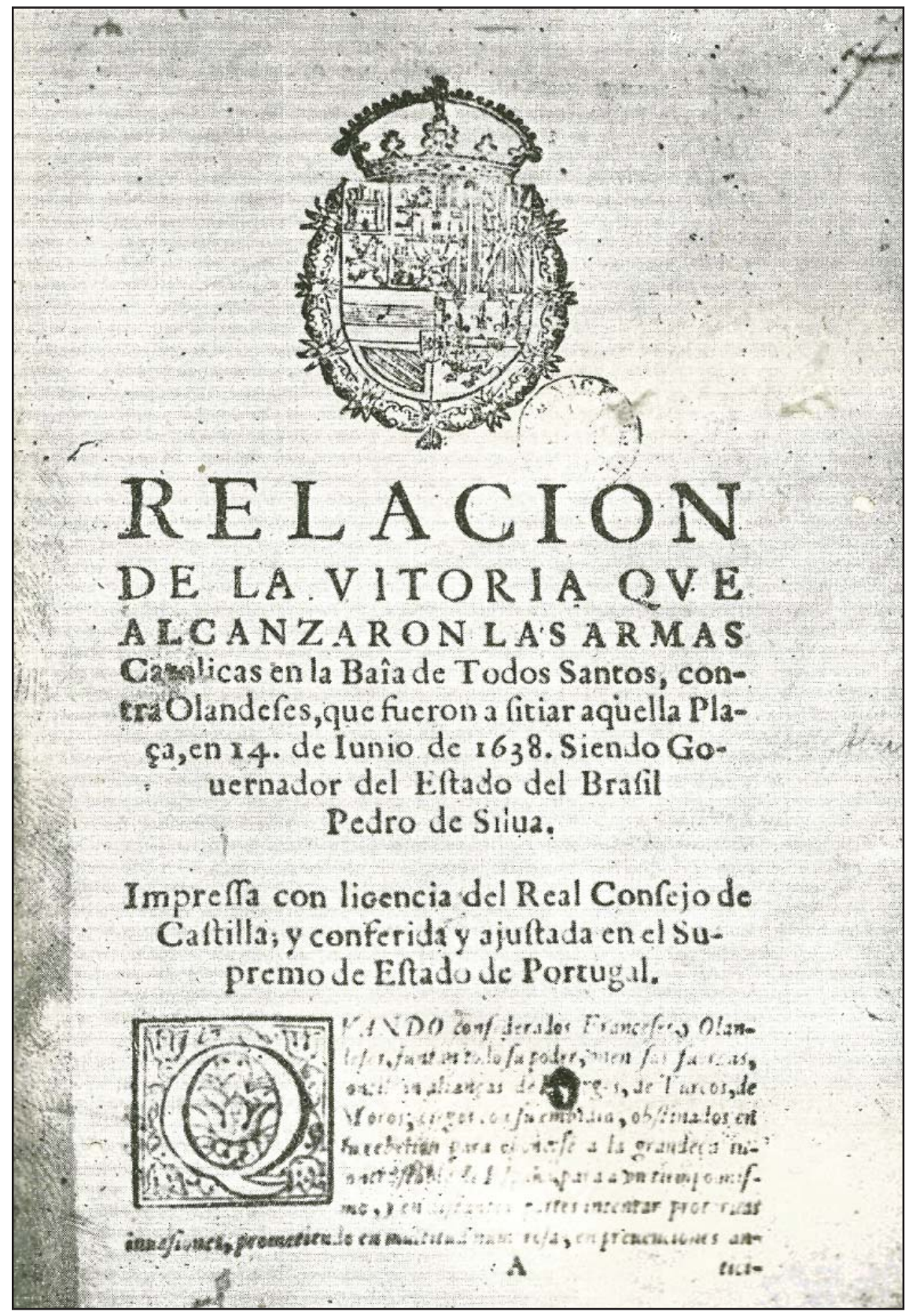

Figura 1 - Folha de rosto da Relacion de la Vitoria que alcanzaron las Armas Catolicas. Biblioteca Nacional do Rio de Janeiro. Exemplar da Coleção Barbosa Machado, volume Notícias Históricas e Militares da América, que compreende desde o ano de 1576 até 1757.

O colofão traz a seguinte informação sobre o impressor: "En Madrid, Por Francisco Martinez, año 1638”. De acordo com José Honório Rodrigues, "trata-se de uma relação de importância militar, onde ao lado da curta descrição da peleja se acentuam vários e importantes fatores de tática e estratégia militar”" Pedro Salvá y Mallen, no Catálogo da Biblioteca de Salvá (n. 3.374), menciona uma edição impressa em Valência, por Iuan Bautista Marçal, que também é de 1638, mas com quatro folhas apenas. Não encontrei exemplar dessa edição valenciana, mas a anotação de Salvá indica que a data no título continuou equivocada, alterada de "14. Iunio" para "16 de março".

Mesmo tendo duas edições quase simultâneas em diferentes cidades espanholas, a Relacion de la Vitoria circulou também em forma de manuscrito, sendo que uma dessas cópias está conservada na Biblioteca da Universidade de Barcelona. O dominicano frei Gaspar Vicenç, prior do Convento de Santa Cata- 
lina de Barcelona, compilou três códices de manuscritos que formam a coleção intitulada Cosas varias y notables sucedidas en estos nuestros tiempos, na qual incluiu uma Relación de la Vitoria que alcançaron las Armas Católicas en la Baía de Todos Santos contra Olandeses en el año del Senhor de 16389. Cotejando a cópia manuscrita com o texto impresso percebe-se poucas diferenças, demonstrando que essa mensagem de unidade política, sob a égide do catolicismo, chegou aos leitores da conturbada Catalunha.

A segunda relação publicada na Espanha intitulou-se Relacion Verdadera, de la Gran Vitoria que han alcanzado en el Brasil la gente de la Baia de Todos Santos, contra los Olandeses. Dase cuenta como les mataron dos mil hombres, y de la gran pressa que les tomaron, haziendo-los embarcar, y dexar el puerto, quitando-les todo el bagaje que lleuauan. O colofẫo traz a seguinte informação: "Impressa con licencia en Seuilla, por Nicolas Rodriguez, en calle de Genoua. Año de 1638”, com quatro folhas. A Relacion de la vitoria que alcanzaron las Armas Catolicas foi, no entanto, considerada a mais importante pelos historiadores brasileiros do século XIX, sendo duas vezes reimpressa naquele século ${ }^{10}$.

A Relacion de la Vitoria, como tantas outras relaçôes, não tem indicação de autor, mas foi a que maior alcance obteve no conjunto bibliográfico sobre as guerras neerlandesas. Em primeiro lugar, porque teve duas impressôes ainda no ano de 1638; em segundo, sua tiragem deve ter sido significativa para a época. Mesmo sendo obra rara, hoje, bibliotecas importantes possuem exemplares desse panfleto e quase todos os catálogos de coleçóes particulares publicados nos séculos XIX e XX trazem-no indicado ${ }^{11}$. Além disso, circulou por meio de diversas cópias manuscritas.

Para entender o alcance da Relacion de la Vitoria deve ser considerado o mais importante aspecto da sua impressão. O seu discurso estava alinhado ao projeto da Coroa espanhola de estabelecer uma monarquia universal católica, suprimindo os interesses nacionais lusitanos. Os historiadores Luis Suárez Fernández e José Andrés Gallego afirmam que a política do Conde-Duque de Olivares foi negativa para Portugal "pues desde el primer momento esperó la colaboración de Portugal en la Unión de Armas y mantuvo un estrecho control sobre el Consejo de Portugal mediante su nominado Diego Soares" 12.

O objetivo de Olivares em relação a Portugal era empregar os tributos cobrados dos portugueses para custear não apenas as guerras contra os neerlandeses no Brasil, mas também os gastos em Flandres, questão militar alheia aos interesses portugueses. Para esses fins, foram criados novos tributos, em Portugal: em 1631 o imposto sobre ofícios e, em 1635, uma taxa extra, de 5\%, sobre as rendas. Em 1637, a introdução do "papel selado" provocou graves distúrbios anticastelhanos em Évora e em outras cidades, reprimidos duramente por ordem de Olivares. Em junho de 1638, preocupado com o curso dos acontecimentos em Portugal, Olivares chegou a afirmar que:

Se ha visto correr el gobierno de Portugal tantos años como sesenta, com tanta separación y división de todo o resto de la monarquía y com tanta graveza de todos ellos para acudir a aquella corona (...) Viendo también la mala orden y disciplina militar con que se gobiernan, no queriendo ajustar a la disciplina de todo el resto de la monarquia. ${ }^{13}$

Fernandez e Gallego observaram que, para o ministro, esses problemas com Portugal "sólo podia resolverse com uma unión más intima entre los reinos"14: a União das Armas Católicas.

Assim, a vitória sobre os neerlandeses na Bahia foi uma oportunidade que Olivares não pôde desperdiçar em seu projeto de União das Armas de Espanha e Portugal. Aquele contexto político originou a Relacion de la Vitoria que alcanzaron las Armas Catolicas en la Baia de Todos Santos, contra Olandeses e, através dele, também podemos compreender porque diversas relações de origem portuguesa não foram impressas. Seu discurso diminuiu os elementos nacionais em prol de uma causa católica. Não eram lusitanos, espanhóis e napolitanos que lutavam contra neerlandeses, mas, sim, as "forças católicas". A Relacion de la Vitoria serviria como um instrumento para legitimar o domínio de Castela sobre Portugal, demonstrando que a união das naçóes católicas havia conseguido derrotar a pretensão neerlandesa de conquistar a capital da América portuguesa. A mensagem é a de que a União Ibérica tornaria Portugal 
mais forte no Ultramar e, por essa razão, o discurso da União das Armas Católicas na publicação de relaçóes de fatos continuou sendo utilizado pelo governo espanhol, como no episódio da armada comandada por Fernando Mascarenhas, Conde da Torre, enviada ao Brasil para combater os holandeses ${ }^{15}$.

Mas quem seria o autor da Relacion de la Vitoria? O que parece não ter sido percebido, até o presente, por nenhum historiador ou bibliógrafo, é que esse texto foi novamente publicado em Madri no ano seguinte e desta vez com o nome do seu autor. Assim, em 1639, a Relacion de la Vitoria aparece, entre as páginas 306 e 328, no livro de D. Juan de Palafox y Mendoza (1600-1650), intitulado Sitio y Socoro (sic) de Fuenterabia (sic) y sucesos del año de mil y seiscientos y treinta y ocho ${ }^{16}$ (Figura 2 e Apêndice).

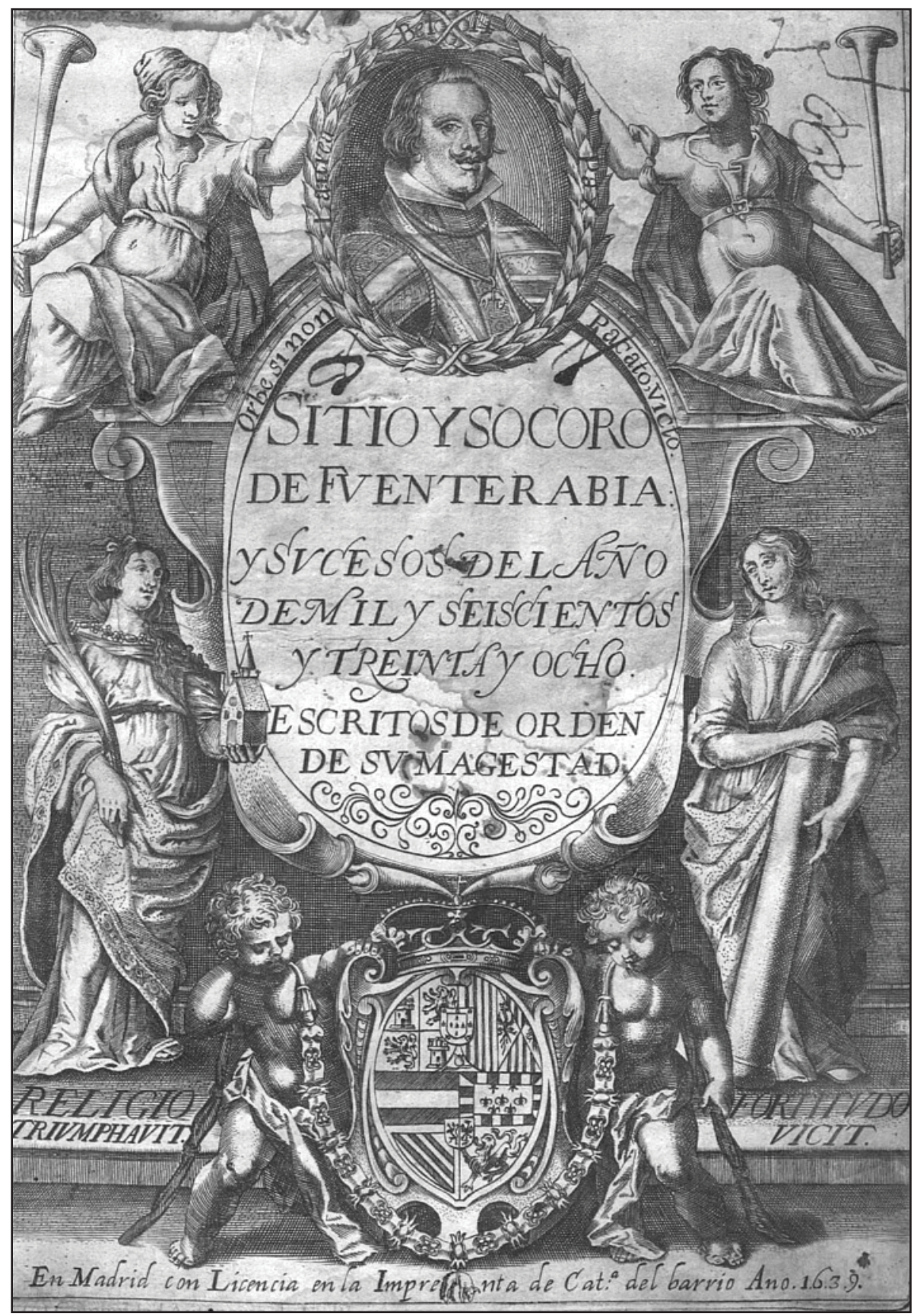

Figura 2 - Folha de rosto de Sitio y Socoro de Fventerabia. Exemplar da Biblioteca Nacional de España. 
Nenhum dos catálogos de publicações referentes às guerras neerlandesas aponta a existência do livro de Palafox, a exemplo do A Bibliographical and Historical Essay on the Dutch Books and Pamphlets Relating to New Netherland and to the Dutch West India Company and to its Possessions in Brazil and Angola, de G. M. Asher, professor de Direito Romano da Universidade de Heidelberg, que o publicou, em Amsterdam, em 1854. A obra de José Honório Rodrigues, Historiografia e bibliografia do domínio holandês no Brasil, publicada em 1949, também não aponta a existência do referido livro. Uma simples comparação entre os textos de 1638 e 1639 confirma, não obstante, tratar-se do mesmo escrito, cuja autoria, identificamos no próprio D. Juan de Palafox y Mendoza.

A biografia de Juan de Palafox y Mendoza é bastante conhecida; entretanto, algumas observaçóes podem contribuir para uma compreensão mais apurada de sua participação na redação da Relacion de la Vitoria. Nascido em Fitero, Navarra, filho de Dom Jaime Palafox, Marquês de Ariza, Palafox y Mendoza estudou em Alcalá de Henares e na Universidade de Salamanca e, em 1626, era deputado da nobreza nas cortes de Monzón. Pouco depois, tornou-se fiscal dos Conselhos de Guerra e Índias, quando iniciou sua vasta produção intelectual. Foi ordenado sacerdote e logo se tornou capelão de Maria Ana de Áustria, irmã de Felipe IV, a quem acompanhou em diversas viagens pela Europa ${ }^{17}$.

Por seus serviços prestados, em 1639, foi apresentado em Madri, por El Rey, como Bispo de Puebla de los Angeles, no Vice Reino de Nova Espanha. Sua mitra diocesana foi confirmada pelo Papa Urbano VIII, em 27 de outubro daquele mesmo ano. A nomeação de Palafox para a diocese de Puebla também incluía objetivos políticos específicos, pois ele fora comissionado para investigar o Vice-rei de Nova Espanha, Dom Diego López de Pacheco Cabrera y Bobadilla, Duque de Escalona e Marquês de Villena, de cuja fidelidade Felipe IV levantava suspeitas. Palafox chegou, em segredo, na Cidade do México na noite de 9 de julho de 1642 e ordenou que Pacheco Cabrera fosse preso, confinando-o no Convento de Churubusco, confiscando e arrematando seus bens e, por fim, remetendo-o a Espanha. Entre 10 de junho e 23 de novembro de 1642, Juan de Palafox ocupou interinamente o cargo de Vice-rei de Nova Espanha. Neste curto período organizou ordenanças para a Universidade, a Audiência e os advogados, aprestando 12 milícias para a defesa do território, visto que temia que as revoluçóes de Portugal e da Catalunha se propagassem pela colônia.

Na Nova Espanha, Juan de Palafox deu demonstraçôes políticas da sua inquietação contra os sentimentos autonomistas lusitanos. O então Vice-rei afirmava que os portugueses no México estocavam armas de fogo e muniçóes, aumentando a tensão com os castelhanos. Nesse cenário, Palafox informou ao Conselho das Índias (Real y Supremo Consejo de Indias) que "Los vezinos castellanos de esta ciudad (...) me dicen a cada passo que andan muy recelossos de los portugueses". Por conta da Restauraçáo de Portugal, em dezembro de 1640, Palafox expulsou todos os portugueses do Porto de Vera Cruz ${ }^{18}$.

Em Puebla fundou o convento de religiosas dominicanas de Santa Inês; redigiu as Constituiçóes para o Seminário de San Juan e erigiu os colégios de San Pedro (para Gramática, Retórica e Cantochão) e o de San Pablo (para graus acadêmicos), dotando-o com uma excelente biblioteca, atualmente denominada Palafoxiana. Criou o colégio de meninas dedicado a Puríssima Concepción, além de dedicar parte dos seus esforços para concluir as obras da Sé Catedral, que consagrou a 18 de abril de 1649. Vacante a Sé Metropolitana, por falecimento, em 1641, do Arcebispo Dom Feliciano de Vega y Padilla, o Cabido eclesiástico elegeu Palafox Arcebispo do México, em 12 de novembro de 1643. Na defesa da sua jurisdição episcopal, entrou em atrito com religiosos regulares, principalmente com a Companhia de Jesus. Devido ao seu protagonismo nessas contendas, encontrou a hostilidade dos jesuítas, o que motivou sua grande aversão a esta Congregação. Em duas ocasiôes, em 1647 e em 1649, representou contra ela, expondo queixas formais ao papa Inocêncio X. Este, sem embargo, não aceitou as censuras apresentadas e tudo o que Palafox obteve foi um informe, datado de 14 de maio de 1648, que instava os jesuítas a respeitar a jurisdição episcopal. Contudo, em 1653, aqueles religiosos conseguiram a transferência de Palafox para a Espanha. No Reino, foi nomeado 
Bispo de Osma, onde morreu a 1 de outubro de 1659, sendo sepultado na Capela do Venerável Palafox, projetada por Juan de Villanueva, em sua Sé Catedral.

Como explicar a grande semelhança entre a Relacion de la Vitória, de 1638, e o livro de Juan de Palafox publicado em 1639? Seria apenas um caso de plágio? Provavelmente, não! No ano em que a ediçáo primitiva foi publicada, Palafox ainda era um oficial do Conselho das Índias, onde tramitavam consultas e informes oriundos do Ultramar Ibérico, incluídos os do Brasil. Enquanto ocupava cargos neste Conselho, Palafox redigiu seus primeiros textos de relevo político, os quais, segundo Antonio Gonzalez de Rosende, "se imprimieron unos, se perdieron otros"19. A Relacion de la Vitoria deve ser um desses papéis que se imprimiram sob anonimato. Não há dúvida, contudo, de que aquele texto foi escrito ou organizado por um oficial do Conselho das Índias, que deve ter sido o próprio Palafox, para que, em seguida, fosse "conferida" com o Conselho Real e o Conselho de Portugal, ou seja, Olivares e Diogo Soares. Além disso, Francisco Martinez (1619-1645), que imprimiu a Relacion de la Vitoria, em Madri, editou também outros textos da autoria de Palafox, publicando, em 1641, os Discursos espirituales del Ilustrissimo Señor Don Iuan de Palafox y Mendoza recogidos por el R.P. Iuan Antonio Velazquez.

A editio princeps do Sitio y socoro de Fuenterabia y sucesos del año de mil y seiscientos y treinta y ocho traz estampado na portada que os acontecimentos ali narrados foram "Escritos de orden de su Magestad". Apesar de trazer a efígie de Felipe IV, subtende-se que a ordem partiu do influente Conde-Duque de Olivares. Para esta demanda política, Juan de Palafox estabeleceu a versão definitiva de quatro relaçóes impressas em 1638, que tiveram grande aceitação entre os leitores, por serem mais baratas e acessíveis que o livro, destinado às classes sociais mais influentes e letradas. Assim, Palafox reuniu nessa obra todas as vitórias militares das armas espanholas em 1638, empregando um estilo narrativo, cujas características evocam as preconizadas nos atuais manuais de redação jornalística, consideradas básicas do estilo informativo: "Poco, o ningun aliño en estilo, sin exornacion los sucessos, ni descripcion las ciudades, fortalezas, y Provincias, desnuda de aquella eloquencia, que va embevida en las grandes historias que enseñan igualmente, y persuaden". O que, em sua modéstia, Palafox chama de "imperfecciones" são, na verdade, as virtudes daquele novo estilo, já posto em prática por relacioneiros e gazeteiros: o da notícia imediata e acessível ao grande público. Palafox despreocupa-se das causas, preferindo relatar "los sucessos desnudos, quales son las batallas y los vencimientos". A credibilidade do relato seria alcançada não só pelo estilo, senão por acharse respaldada por crédito oficial:

Afiança el credito de la verdad, y ajustamiento desta relacion, el escrivirse de orden de su Magestad, pues las noticias que en ella se contienen son las mismas que han dado los Generales, los Cabos, y las que resultan de las Consultas, y papeles de los oficios por donde ha corrido esta materia. ${ }^{20}$

As fontes que menciona seriam as mesmas que havia manuseado, um ano antes, nas quatro relaçôes impressas.

A Relacion, publicada por Palafox em 1639, apresenta algumas diferenças em relação ao texto impresso em 1638. O primitivo contém 29 parágrafos, enquanto o de 1639, apenas 15. No texto de 1639, foram suprimidos, não obstante, o primeiro parágrafo e os que se encontravam entre o $25^{\circ}$ e $29^{\circ}$. Em sua essência, o texto da Relacion de la Vitoria foi conservado praticamente ipsis litteris; mas, foi excluída a exortação das armas católicas, em itálico, do parágrafo 1, concluído, agora, com a seguinte afirmação, possivelmente de autoria do próprio Palafox: "De quatro [batalhas] ha salido relación, mas llena de verdad, que de arrogancia, la de Fuente-Rabia saldra presto, de la Baia la ofrece mi afecto". Por outro lado, o texto da edição de 1639 traz alguns acréscimos em relação à sua matriz primitiva. Palafox acrescentou, na seção central da Relacion, uma apologia à União das Armas Católicas luso-espanholas, em oposição à heresia das Províncias Unidas: 
Poniendoles delante la perfidia del enemigo, su crueldad, obstinados, y rebeldes á Dios, y á su Rey: que esteba librado en su esfuerzo el vivir con honra, y libertad debajo de la mano de un Principe justo, Catolico, y Religioso, ó en servidumbre durissima en poder de hombres viles, hereges, y tiranos. Que el numero no habia que temerlo, pues este nunca vence al valor; gente colecticia, marineros, grumetes sin honra, sin incitamento alguno de virtud, ni de honor, lo mas despreciado y soez de los Estados rebeldes. Representaba la valentia de las Naciones Castellana, y Portuguesa, enseñadas, no solo á vencer por guarda sus casas, que los animales mas debiles saben, y suelen defender hasta la ultima desesperación; sino á conquistar las Naciones mas remotas, y hacer formidable su nombre en toda la circunferencia de la tierra. ${ }^{21}$

Os parágrafos 25 ao 29, excluídos da edição de 1639, indicam a origem da Relacion que narrou a "tan señalada vitoria" contra os neerlandeses no Brasil. O Governador do Brasil, Pedro da Silva, enviou aviso por duas vias; a primeira, pelo Tenente Francisco Peres de Souto e a segunda, por meio do Capitão Pedro de la Carrera y Arenas. A 27 de agosto, os despachos foram entregues a Diogo Soares, Secretário de Estado do Conselho de Portugal. Acompanhado pelos dois militares e pelo Conde-Duque de Olivares, seu cunhado, Diogo Soares levou "las norabuenas (...) al Grande Atlante del Orbe Hispano". Felipe IV concedeu audiência particular aos emissários das guerras no Brasil para, em seguida, retribuir mercês aos que participaram da vitória contra Nassau.

Com as informações prestadas por Palafox, tanto nos parágrafos finais da relação de 1638, quanto no proêmio ao leitor do livro de 1639, é possível traçar a genealogia completa da Relacion de la Vitoria. Palafox organizou o texto e o enquadrou no discurso político de Olivares, mas as informaçóes presentes tiveram origem entre os militares que lutaram contra Nassau. Duarte de Albuquerque Coelho afirmou que, após o sucesso na defesa da Bahia,

Embiaronse luego tres caravelas de aviso a España, i en cada una ivan dos personas: una con cartas del Governador i Capitan General, que fue el Capitan Pedro Carrera de Arenas, i el Teniente de la Artilleria Francisco Perez de Soto con las del Conde. Estos llegaron primero. En la segunda, con las del Governador iva el Capitan Sebastian de Lucena, i con las del Conde el Capitan don Gregorio Cadena. En la tercera fue solo el Licenciado Gregorio Gomez Madera, que avia cabado de servir de Auditor General de la gente de Pernambuco, quedandole sucediendo el Licenciado Simon Alvarez de la Peña. ${ }^{22}$

Manuel de Vasconcelos, escrivão da Fazenda Real de Pernambuco, que acompanhou o Conde Bagnuoli à Bahia, afirmou em manuscrito, conservado na Biblioteca Pública de Évora, que "A Relação q der o thenemte g. ${ }^{1}$ da Artelh. ${ }^{\text {ria }}$ Fran. ${ }^{\text {co }}$ Peres de Sotto sera a uerdadeira; porq falara Como quẽ o emtemde (sic); (...) os demais uão sobernados; e antes q bebão aguoa Desse Reino, sera neçess. ${ }^{\text {ro }}$ q uzem da preuenção da cobra" ${ }^{23}$. Deve-se entender que Manoel de Vasconcelos, naquele contexto, nutria rancores contra a família Cadena, tanto o pai Pedro quanto o filho Gregório, este último enviado no segundo navio com os avisos para a Espanha. Segundo Vasconcelos,

por se me não paGuarẽ meus ordenados uençidos; q se me deuem tres mil e tamtos Cruzados A Comta dos quais o prou. ${ }^{\text {or }}$ Mor q oie Serue P. ${ }^{\circ}$ de Cadena Vilasancty me dar Couza algũa; por eu não Ser daquelles q a elle ou a seu f. ${ }^{\circ}$ Dom greg. ${ }^{\text {ro }}$ largão mais de a metade dos Conhesimentos em forma q se passão sobre o tizoureiro g. ${ }^{1}$ deste estado fran. ${ }^{\text {co }}$ do Amaral; q he da sua facsção (sic).$^{24}$

Decerto, a Relacion de la Vitoria foi redigida por Palafox, a partir dos informes do Governador Pedro da Silva, do Conde de Bagnuoli e, particularmente, de Peres de Souto e do Capitão Arena. No Arquivo Histórico Ultramarino, em Lisboa, encontramos uma carta manuscrita do Governador, seguida de uma "Relação dos Ministros Superiores de primeira e segunda plana e mais officiais e soldados que no Sitio que o Inimigo pôs a esta Cidade da Bahia em 16 de abril 638 a ajudarão a defender". Seria esta a relação que Pedro da Silva enviou por intermédio de Peres de Souto? É possível, mas também foi publicada 
na Espanha uma carta que o Governador enviou para o Conde de Nassau, em 13 de maio de 1638, indicando que outros informes de Pedro da Silva foram remetidos a Madri ${ }^{25}$. Não localizamos qualquer relato do próprio punho do Conde de Bagnuoli em 1638, mas é possível que se trate da própria Relação do Médico Fernandes de Figueiredo, por sua proximidade com o militar napolitano ${ }^{26}$.

Há outras fontes que Palafox manejou para escrever a Relacion de la Vitoria. Talvez o próprio Tenente Peres de Souto tenha descrito os acontecimentos na Bahia, o que explica a relevância que esse militar assume na narrativa de Palafox, que o menciona nos parágrafos 10, 14 e 26. No Archivo Historico Nacional, em Madri, na Colección Documentos de Índias, existem três relaçôes manuscritas sobre o Cerco de 1638. A primeira, datada de julho de 1638, intitula-se Victorias alcanzadas contra los holandeses em Todos los Santos; a segunda, de agosto, chama-se Victoria de la bahía de Todos los Santos contra los holandeses; a terceira, de 3 de dezembro de 1638, Victoria de las armas catolicas em el sitio del Brasil. Esta ultima trata-se de mais uma cópia manuscrita da Relacion de la Vitoria ${ }^{27}$.

A partir dos informantes e das fontes utilizadas por Palafox é possível entender as limitaçóes do texto impresso. Sua narrativa apresenta informaçóes dos acontecimentos militares em Salvador e do entorno da capital, como Vila Velha e Itapagipe, mas silencia sobre os episódios ocorridos durante a investida de Nassau no Recôncavo Baiano. Deve-se considerar que os dois militares enviados à Espanha eram nascidos na Europa e militavam no Exército de Pernambuco, entrando em Salvador apenas no calor da batalha. Por essa razão, não conheciam o Recôncavo Baiano, região ignorada no texto da relação.

A Relacion de la Vitoria foi publicada apenas em fins de setembro de 1638, visto que o seu derradeiro parágrafo traz a notícia de que a 7 de setembro daquele ano partira de Lisboa a Armada do Conde da Torre, D. Fernando Mascarenhas, com o objetivo de ser o "assombro del Rebelde del Norte en el Brasil'. O conteúdo da Relacion não fornece, apenas, elementos para a compreensão da política editorial da Espanha sob o Conde Duque de Olivares; trata-se, também, de um texto fundamental para a própria história e a geografia do Cerco de Nassau em 1638, pois apresenta preciosas informaçóes toponímicas dos arredores de Salvador.

Palafox confirma o ataque de Nassau na noite de 14 de abril, quando foram avistadas velas à altura de Itapoã, a três léguas do núcleo urbano. Além disso, o autor foi o único a utilizar, segundo pude identificar, a expressão "Arrayal Viejo", ou Arraial Velho. Trata-se do antigo Arraial do Rio Vermelho, mandado construir pelo Bispo D. Marcos Teixeira de Mendonça, ao norte da cidade, durante a Invasão de 1624. O emprego dessa expressão confirma a real localização geográfica do Arraial do Rio Vermelho, ou do Bispo, em 1624 (Arraial Velho, quatorze anos depois), ou seja, que não estava sediado no atual bairro do Rio Vermelho, mas, no atual Largo do Tanque, por onde passava o rio Camurujipe ${ }^{28}$. O trajeto feito pelas tropas nassovianas comprova a localização do Arraial no atual Largo do Tanque, uma vez que seus soldados foram desembarcadas na Barra de Pirajá. Dali, a 18 de abril, informa Palafox no quinto parágrafo, os neerlandeses marcharam "por las campinas, camiño del Arrayal Viejo". As "campiñas”, não resta dúvida, trata-se do atual bairro de Campinas de Pirajá. Até hoje existe a Estrada das Campinas, que segue em direção ao Largo do Tanque ${ }^{29}$.

Essa estratégia comprova que Nassau conhecia bem os locais que poderiam servir para a defesa de Salvador. Primeiro, destruiu o aldeamento do Espírito Santo e, já nas imediações da capital, ocupou a sede do antigo Arraial do Rio Vermelho que, por volta de 1638, não deveria ter mais do que algumas cabanas ocupadas por africanos que tentavam fugir da escravidão. As tropas de Nassau não demoraram no Arraial e passaram para a "colina do Padre Ribeiro", no atual bairro da Soledade. Por isso, as trincheiras construídas no bairro de Santo Antonio Além do Carmo tornaram-se o último ponto defensável pelo norte de Salvador.

No sexto parágrafo, a relação de Palafox dá voz a uma mulher, "natural do Brasil", que, ao saber que seu marido, um oficial militar, havia desertado de seu posto, não lhe permitiu que entrasse em casa, trancando a porta. A esposa afirmou "que no habria puerta a hombre, que tan bajamente habia entregado 
el puesto que le estaba encargado, y que quando viniera hecho pedazos, por haber sido en defensa de la Religion Catolica, y de su Rey, alegre, y gustosa le recibiera". Essa anedota pode ser interpretada como uma estratégia discursiva simples, mas hábil, do autor para animar o sentimento religioso dos leitores, legitimando, através da declaração da esposa, o discurso da luta pela Igreja e pela União da Coroa.

Palafox descreve o primeiro ataque neerlandês às 20 horas do dia 21 de abril, bem como a utilidade das trincheiras construídas em menos de quinze dias, "acudiendo a la obra los Religiosos, los Clerigos, Estudanties, mugeres, y muchachos con grande conformidad”. Após o fracasso do dia 21, Nassau "hizo um parlamento al Egercito", prometendo aos soldados que não haveria dificuldades em tomar Salvador e que eles poderiam ficar com o saque. Nassau precisava conquistar as trincheiras de Santo Antonio Além do Carmo, mas dividiu seu exército, posicionando apenas 1600 homens na linha de frente, para avançar sobre a trincheira, mantendo o resto na retaguarda, "cerca de la Casa Quemada" - provavelmente o atual Largo do Queimado, próximo a Soledade. Essas excepcionais informaçóes toponímicas sobre Salvador, que Francisco Adolfo de Varnhagen não registrou na História das Luctas contra os Hollandezes no Brazil, confirmam que Palafox teve acesso a fontes que descreveram com precisão a geografia da capital, mas que pouco conheciam o Recôncavo Baiano.

A relação descreve também o segundo e último ataque neerlandês, efetuado às 20 horas do dia 18 de maio, contra as trincheiras de Santo Antonio. Naquele momento, as forças em contenda haviam chegado a um impasse, mas a vantagem geográfica estava com os defensores, na medida em que os neerlandeses tinham sido obrigados a se posicionar numa parte baixa, entre a Soledade e o Santo Antonio, e que precisariam escalar um fosso para alcançar as trincheiras portuguesas. No Santo Antonio estavam o Governador Pedro da Silva, o Conde de Bagnuoli e os contingentes de Luiz Barbalho, Lourenço de Brito, Francisco de Souto, além de outros capitães.

Para tentar acabar com o impasse e assumir alguma vantagem, Nassau ordenou que o contingente estacionado em Queimado avançasse. Foi a ocasião em que os contingentes dos Sargentos-mores Antonio de Freitas da Silva e Francisco Duarte, em conjunto com os do Mestre de Campo Heitor de la Calce - que havia retirado suas forças da regiáo das Palmas -, saíram pelo Dique e surpreenderam as tropas neerlandesas pelo flanco direito. Essa investida resultou na morte de mais de trezentos inimigos. Foi essa batalha que definiu a vitória das "forças católicas". Em seguida, o contingente de Heitor de la Calce socorreu os fortes de São Diogo e de Santo Antonio da Barra, protegendo Salvador pelo sul ${ }^{30}$. Ao Conde de Nassau coube retirar seus contingentes para Pernambuco.

A Relação por Meio Breve e Verdadeira, de Moniz Telles, seguida pela Relação Diária do Cerco da Baí, de Cadena Vilhasanti, ainda constituem os mais importantes textos para a história do sítio comandado por Nassau, em 1638. Mas, a leitura da Relacion de la Vitoria que alcanzaron las Armas Catolicas en la Baia de Todos Santos, contra Olandeses continua fundamental para e entendimento daquele evento, bem como da dialética impressos-manuscritos na Península Ibérica, e para a interpretação da política editorial de Olivares.

\section{Notas}

${ }^{1}$ GALINDO, Marcos; GUERREIRO, Bartolomeu; TEENSMA, Benjamin Nicolas; IGLESIAS MAGALHÃES, Paulo Antonio (Orgs.). Episódios baianos: documentos para a história do período holandês na Bahia. Recife: NÉCTAR, 2010. p. 229-262.

${ }^{2}$ COUTINHO, Antônio Xavier da Gama Pereira. A iniciativa dos portugueses na defesa da Bahia, em 1638: esboço de nótula histórica sobre documentos inéditos. Porto: Tip. Diário do Porto, 1937.

${ }_{3}^{3}$ ÁLVARES, Fernando Bouza. Corre Manuscrito: una historia cultural del Siglo del Oro. Madrid: Marcial Pons, 2001. p. 143,147 e 163.

${ }^{4}$ ARANDA, Francisco José; PÉREZ, José Damião Rodrigues (Eds.). De Re Publica Hispaniae: una vindicación de la cultura política en los reinos ibéricos en la primera modernidad. Madrid: Sílex, 2008. p. 45 e 46. 
${ }^{5}$ Idem, p. 45 e 46.

${ }^{6}$ SCHAUB, Jean-Frédéric. Le Portugal Au Temps Du Conte-duc D’Olivares (1621-1640). Madrid: Casa de Velázques, 2001. p. 247.

${ }^{7}$ RODRIGUES, José Honório Rodrigues. Historiografia e bibliografia do dominio holandês no Brasil. Rio de Janeiro: Departamento de Imprensa Nacional, 1949. p. 243.

${ }^{8}$ SALVÁ Y MALLEN, Pedro. Catálogo de la biblioteca de Salvá. Valencia: Imprenta de Ferrer de Orga, 1872. Tomo 2, p. 619. É notório o equívoco quanto à data indicada no título da Relação. O cerco de Nassau aconteceu entre abril e maio, mas no texto da edição de Madrid está impresso “14. de Iunio”. A Biblioteca Nacional do Rio de Janeiro possui dois exemplares na Coleção Barbosa Machado; um, no volume intitulado Notícias Históricas e Militares da América, que compreende desde o ano de 1576 até 1757. Em ambos existem notas manuscritas corrigindo a data do Cerco da Bahia. Ao pé da folha 3 "Al principio de la Relacion donde dize 14. de Iunio, há de dezir 16. de Março”. No segundo exemplar a data também foi corrigida à mão, corretamente, para 14 de abril.

${ }^{9}$ Biblioteca de la Universidad de Barcelona. Ms. 1008-1010. VICENÇ, Fr. Gaspar, O.P. Cosas varias y notables sucedidas en estos nuestros tiempos. Esse códice tem o subtítulo Memorias del succeit des de l'any 1631 fins 1639. Documento 131; Fls. 332-334v (329-331), Relación de la vitoria que alcançaron las armas católicas en la Baía de Todos Santos contra olandeses en el ańo del Senhor de 1638.

${ }^{10}$ Relacion de la vitoria que alcanzaron las Armas Catolicas en la Baia de Todos Santos, contra Olandeses, que fueron a sitiar aquella Plaça, en 14. de Iunio [sic] de 1638. Siendo Gouernador del Estado del Brasil Pedro de Silua. Impressa con licencia del Real Consejo de Castilla, y conferida y ajustada en el Supremo de Estado de Portugal. In: Annaes da Bibliotheca Nacional, Vol. 20, p. 133-142. Rio de Janeiro, 1889. In: Revista do Instituto Histórico e Geográfico Brasileiro, tomo 22, p. 331-337. Rio de Janeiro, 1859.

${ }^{11}$ TERNAUX-COMPANS, Henri. Bibliothèque américaine: ou, Catalogue des ouvrages relatifs à l'Amérique. Paris: Arthus Bertrand, 1837, p. 106. ELLIOTT, Danial. Maritime history: a hand-list of the collection in the John Carter Brown Library (1474 to ca. 1860). Providence: The John Carter Brown Library, 2005, p. 179. HORCH, Rosemarie Erika. Bibliotheca Universitatis: Acervo Bibliográfico da USP - Século XVII. São Paulo: Edusp, 2002, p. 1244.

${ }^{12}$ FÉRNANDEZ, Luis Suárez; GALLEGO, José Andrés. La Crisis de la hegemonía española, siglo XVII. Madrid: Ediciones RIALP, 2010. p. 543.

${ }^{13}$ Archivo General de Simancas. Est. Leg 2660, Junta de Portugal e Documento de Olivares, 12.06.1638.

${ }^{14}$ FÉRNANDEZ, Luis Suárez; GALLEGO, José Andrés. La Crisis de la hegemonía española, siglo XVII. Op. cit, p.543.

${ }^{15}$ Relacion verdadeira y carta nueva enviada del Brasil por um artillero, Clamado Bernardo Munnoz, a un hijo suo, dando le cuenta de una grande victoria que las armas catholicas han tenido sin pensar en el sitio del Brasil, al 29. Novembre 1638. Madrid 1639.

${ }^{16}$ PALAFOX Y MENDOZA, Juan de. Sitio, y socoro de Fuenterabia y sucessos del año de treinta y ocho. Madrid: La Imprenta de Catalina del Barrio, 1639, p. 306-328. Na segunda edição, a grafia do título aparece corretamente: Sitio, y socorro de Fuente-Rabia y sucessos del año de treinta y ocho. In: Obras del Ilmo. Iuan de Palafox y Mendoza, Obispo de Osma. Tomo VI. Madrid: por Melchor Alegre, 1667. Esse texto teve terceira edição: Obras del Ilustrissimo, Excelentissimo, y Venerable Siervo de Dios Don Juan de Palafox y Mendoza. Tomo X. Madrid: En la Imprenta de Don Gabriel Ramirez, 1762, p. 214-222. Segundo Palau, a segunda edição das Obras de Palafox "es preferible por su belleza tipográfica y corrección”. DULCET, Antonio Palau y. Manual del librero hispano-americano: inventario bibliográfico de la producción cientifica y literaria de España y de la América latina desde la invención de la imprenta hasta nuestros dias, con el valor comercial de todos los artículos descritos, Volume 12. Madrid: Libreria Anticuaria, 1927. Por essa razão, o fac-símile aqui apresentado é o da edição de 1762 (ver Apêndice).

${ }^{17}$ ROSENDE, Antonio Gonzalez de. Vida del Ilustrissimo y Excelentissimo Señor don Juan de Palafox y Mendoza. Madrid: Imprenta de Don Gabriel Ramirez, 1762. p. 21 a 27.

${ }^{18}$ ROSENDE, Antonio Gonzalez de. Vida del Ilustrissimo... Op. cit., p. 550. ISRAEL, Jonathan Irvine. Empires and entrepots: the Dutch, the Spanish monarchy, and the Jews, 1585-1713. Londres: Hambledon Press, 1990. p. 311-315.

${ }^{19}$ ROSENDE, Antonio Gonzalez de. Vida del Ilustrissimo... Op. cit., p. 22.

${ }^{20}$ PALAFOX Y MENDOZA, Juan de. Sitio, y socoro de Fuenterabia y sucessos del año de treinta y ocho. Op. cit. [1639].

${ }^{21}$ PALAFOX Y MENDOZA, Juan de. Sitio, y socoro de Fuenterabia y sucessos del año de treinta y ocho. Op. cit. [1639], p. 319-320.

${ }^{22}$ COELHO, Duarte de Albuquerque. Memorias Diarias de la Guerra Del Brasil por Discurso de Nueve Años. Madrid: Diego Diaz de la Carrera, 1654. fls. 283v-284.

23 Biblioteca Pública Municipal de Évora. Códice CXVI/ 2-3, Fls. 93-96v. Relasão do q tem susedido na bahia atee 5 de junho de 638 annos. Manuel de Vasconcelos, Bahia, 05.06.1638.

${ }^{24} \mathrm{Idem}$. 
${ }^{25}$ Arquivo Histórico Ultramarino. Catálogo Luísa da Fonseca; Caixa 7, Documento 799, Carta do governador do Brasil Pedro da Silva para S. Magde. com a relação das pessoas que se assinalaram na defesa da Bahia contra o conde de Nassau. Bahia, 12 de junho de 1638; Documento 800, Relação dos ministros e mais oficiais que no cerco da Bahia em 16 de Abril de 1638, ajudaram a defender aquela praça. 10 de junho de 1638. Memorial histórico español: coleccion de documentos, opúsculos y antigüedades que publica la Real Academia de Historia. Madrid: La Imprenta Nacional, 1862. Tomo XV, p. 9-13.

${ }^{26}$ GALINDO, Marcos; GUERREIRO, Bartolomeu; TEENSMA, Benjamin Nicolas; IGLESIAS MAGALHĀES, Paulo Antonio (Orgs.). Episódios Baianos. Op. cit., p. 263-274.

${ }^{27}$ Archivo Historico Nacional. Colección Documentos de Indias, Diversos-Colecciones, 26. Respectivamente, documentos com os número, 75, 76 e 80.

${ }^{28}$ IGLESIAS MAGALHÃES, Pablo Antonio. "Equus Rusus": a Igreja Católica e as guerras neerlandesas na Bahia (16241654). 2010. Tese (Doutoramento em História). Programa de Pós-graduação em História, Universidade Federal da Bahia, Salvador, 2010. Volume 1, p. 55-59.

${ }^{29}$ A estrada das Campinas possui uma bifurcação, as atuais Rua Engenheiro Austricliano e a Avenida Nestor Duarte, que, em seguida, tornam-se novamente uma única via, já nas proximidades do Largo do Tanque.

${ }^{30}$ Há aqui uma diferença entre as ediçôes de 1638 e 1639. Na primeira, no parágrafo 18, está escrito "fuertes de S. Diego", enquanto a segunda foi retificada, apontando os "fuertes de San Diego y San Antonio".

\section{Referências bibliográficas}

ÁLVARES, Fernando Bouza. Corre Manuscrito: una historia cultural del Siglo del Oro. Madrid: Marcial Pons, 2001.

ARANDA, Francisco José; PÉREZ, José Damião Rodrigues (Eds.). De Re Publica Hispaniae: una vindicación de la cultura política en los reinos ibéricos en la primera modernidad. Madrid: Sílex, 2008.

COELHO, Duarte de Albuquerque. Memorias Diarias de la Guerra Del Brasil por Discurso de Nueve Años. Madrid: Diego Diaz de la Carrera, 1654.

COUTINHO, Antônio Xavier da Gama Pereira. A iniciativa dos portugueses na defesa da Babia, em 1638: esboço de nótula histórica sobre documentos inéditos. Porto: Tip. Diário do Porto, 1937.

DULCET, Antonio Palau y. Manual del librero hispano-americano: inventario bibliográfico de la producción científica y literaria de España y de la América latina desde la invención de la imprenta hasta nuestros dias, con el valor comercial de todos los artículos descritos. Madrid: Libreria Anticuaria, 1927. volume 12 .

ELLIOTT, Danial. Maritime history: a hand-list of the collection in the John Carter Brown Library (1474 to ca. 1860). Providence: The John Carter Brown Library, 2005.

FÉRNANDEZ, Luis Suárez; GALLEGO, José Andrés. La crisis de la hegemonia española, siglo XVII. Madrid: Ediciones RIALP, 2010.

GALINDO, Marcos; GUERREIRO, Bartolomeu; TEENSMA, Benjamin Nicolas; IGLESIAS MAGALHÂES, Paulo Antonio (Orgs.). Episódios Baianos: documentos para a história do período holandês na Bahia. Recife: NÉCTAR, 2010.

HORCH, Rosemarie Erika. Bibliotheca Universitatis. Acervo Bibliográfico da USP. Século XVII. São Paulo: Edusp, 2002.

IGLESIAS MAGALHÃES, Pablo Antonio. "Equus Rusus": a Igreja Católica e as guerras neerlandesas na Bahia (1624-1654). 2010. Tese (Doutoramento em História). Programa de Pós-graduação em História, Universidade Federal da Bahia, Salvador, 2010.

ISRAEL, Jonathan Irvine. Empires and entrepotts: the Dutch, the Spanish monarchy, and the Jews, 1585-1713. Londres: Hambledon Press, 1990. 
PALAFOX Y MENDOZA, Juan de. Sitio, y socoro de Fuenterabia y sucessos del año de treinta y ocho. Madrid: La Imprenta de Catalina del Barrio, 1639.

RODRIGUES, José Honório Rodrigues. Historiografia e bibliografia do dominio holandês no Brasil. Rio de Janeiro: Departamento de Imprensa Nacional, 1949.

ROSENDE, Antonio Gonzalez de. Vida del Ilustrissimo y Excelentissimo Señor don Juan de Palafox y Mendoza. Madrid: Imprenta de Don Gabriel Ramirez, 1762.

SALVÁ Y MALLEN, Pedro. Catálogo de la biblioteca de Salvá. Valencia: Imprenta de Ferrer de Orga, 1872.

SCHAUB, Jean-Frédéric. Le Portugal Au Temps Du Conte-duc D’Olivares (1621-1640). Madrid: Casa de Velázques, 2001.

TERNAUX-COMPANS, Henri. Bibliothèque américaine: ou, Catalogue des ouvrages relatifs à l'Amérique. Paris: Arthus Bertrand, 1837. 
Apêndice

214

STTIO, Y SOCORRO

\section{A P I T U L O XXXIV. GUERRA EN LATARTE DEL BRASIL.}

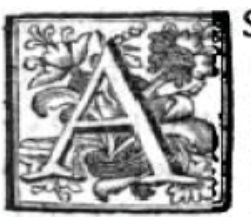

SSISTIDA la caufa Catolica de fu Mageftad con tan particular providencia de Dios en Flandes, y en Italia ; no fue menor el auxilio que experimenró en el Brafil, adonde luego que llegó d avifo al Gobernador Pedro de Silva, de que el Olandes eftaba en el rio de San Francifco haciendo carnes, harinas, $Y_{i}$ otros refrefcos, infirió prudentemente, que fería con defignioo de ir fobre la Bahía de Todos Santos, por hallarfe diftante del rio de San Francifco quarenta y una leguas. Avisó con eftoá toda diligencia al Conde de Bańolo, queeftaba alojado en la Torre Gracia de Avila, catorce leguas á la par del Norte de la Ciudad, de que el enemigo eftaba tan cerca, y que convenia, que con toda fu gente vinieffe para tratar de la defenfa de aquella Plaza. Vifitó los Almacenes, reconociendo las armas, municiones, y pertrechos que en ellos habia; y no pareciendo baftantes, mandó fabricar otros de nuevo. Tambien reconoció los baftimentos, $Y_{i}$ pareciendo pocos, mandó conducir,y comprar muchos mas, ayudan- 


\section{DE FUENTE-RABIA.}

dando á ello con fu hacienda, y á fu imitacion el Obifpo Don Pedro de Silva y Sampayo con 2 y. ducados. Lorenzo de Brito Correa con 6oof. maravedis, mucho ganado, vino, aceyte, $y_{i}$ otros generos; y el Proveedor Conftantino Cadena de Villafanti con dos mil ducados, con que de todo fe fue haciendola prevencion necefaria para hallarfe baftecido para qualquiera fitio, por largo que fueffe. Reconoció las fortificaciones hechas, y. mandó hacer orras, repartiendo la guardia , obras, y pueftos á las perfonas de mayor fatisfacion que tenia en fu compańia.

2 Dif́puefto todo lo necefario, llegó el Conde de Bañolo, Capitan General de la Artilleria ,y Caballeria del Egercito de Pernambuco, y Macfe de Campo General de èl con ochocientos hombres, á quince del mifmo mes, á Villavieja , media legua de la Bahía : y teniendo avifo el Gobernador, partió á verfe con él á conferir todo lo difpuefto, y affentar la forma que fe habia de tener en alojar la gente. Eligieronfe los medios mas apropofito para la difpoficion, preyencion, y egecucion de to do. Y á catorce en la noche tuvo avifo el Gobernador, que parecian muchas velas fobre Atapoan, un Islco en la entrada de la Barra de la Bahía en la punta del Norte, diftante de la Ciudad un quarto de legua. l'ufofe el Egercito en arma, y envió el Gobernador diverfas tropas de caballos, y Compañias de Infante ria , á impedir que no defembarcaffe el enemigo, y ocupar los pueftos mas importantes para entretenerle, fi configuieffe echar gente en tierra. Con los vientos contrarios fe detuvo el rebelde dos dias, hafta que á diez y feis por la tarde entró en la Bahía con una Armada de quarenta y cinco velas, veinte y cinco galeones de porte, y los demás pataches, lanchas, y barcazas, y en ellas feis mil hombres da guerra, tren de artilleria, y todo lo necefario para formar un fitio á cargo del Conde Mauricio de $\mathrm{Na}$ fao. Fue caminando por la punta de Monferrate, y doblada fe abanzó un poco adelante, con intento de echar gente en tierra al anochecer, media legua de la Barra de Piraja, porque no fueffe ofendido de las plataformas de la Barra, y del fuerte de San Bartolomé.

3 Afsi como el enemigo iba doblando la punta de San Arconio, y entrando por la Bahía, fueron figuiende nueftros rercios aquella mifma vuelta, hafta la Barra de Piraja, donde atajados, por no tener en que pafar, faltó en tierra el enemigo, fin 
2.16

SITIO, Y SOCORRO

haber quien $f_{e}$ lo impidieffes $y$ por fer mala la playa, Ilena de. abrojos, y piedras, parecióá los Cabos de nueftro Egercito, que no convenia pafar adelante, fino que fe guarnecieffe el fuerte de San Bartolomè , como fe hizo, y defde San Bartoloméá Agua de Meninos. Marchó la demás gente, y la que iba llegando al Ingenio del Capitan Diego Moniftelles, diftante dos leguas de la Ciudad, adonde intentaba oponerfe al enemigo.

4 A diez y fiete de Marzo por la mañana marcharon el Go* bernador, y el Conde con alguna Caballeria , ć Infanteria al Ingenio, dejando la Plaza , y demás pueftos guarnecidos con la gente necefaria. Aquella noche ocupó el enemigo el alto del Ingenio, lugar fuerte por naturaleza, y en él fe fortificó. Quando legaron los nueftros, y vieron ocupado, y fortificado aquel lugar, defcó el Gobernador defabjar al enemigo. Hizofe Confejd fobre efto, y fe refolvió, que era lo mas acertado defender los pueltos exteriores de la Plaza, cortar los caminos, é impedir que no fe aprovechaffe de cofa alguna de la Campaña. Pufofe todo en egecucion con grande cuidado, $y$ vigilancia , y defeando el Gobernador tomar un prifionero, y no habiendolo podido confeguir con la primera orden, propufo premios á quien hicieffe eftc fervicio al Rey, con que fueron tantos los que fe trageron, facandolos de dentro de las mifmas fortificaciones del snemigo, que folo el Capitan Sebaftian de Soto trajo de una vez quarenta Olandefes.

5 A diez y ocho tuvo avifo el Gobernador, que el enemigo venia por las campińas, camino del Arrayal Viejo, y pareciendo conveniente falirle á recibir fuera de la Ciudad, falieron él, y el Conde de Bańolo marchando con los tercios: y en el barrio de San Antonio acordaron, que el Gobernador volvieffe á la Ciudad, por fer en ella necefaria fu Perfona para prevenir lo mas importante á fu defenfa, y el Conde con la gente mas efcogida marchaffe, como lo hizo, al Arrayal Viejo, y reconociendole, halló que no habia llegado á él el enemigo, y dejan do la gente que pareció baftante en los mas importantes pueftos del camino, con la demás marchó al barrio de San Antonio. El dia figuiente por la mańana falió el Olandes de fus fortificaciones, marchando la vuelta de la Ciudad con mucha orden por el camino del Arrayal Viejo, que era folo por donde podia hacer dańo, cvisando el que podia recibir de las trincheras del Azude.

$\mathrm{Pa}-$ 
Pareció al Gobernador, que era necefario enviar luego á prevenir , y ocupar el puefto de San Antonio al Maefe de Campo Don Fernando de Ludeña con fu tercio, y otra Infanteria Portuguefa. Egecutólo afsi con grande valor, y vifto quan importante era efte puefto, y que eftaba muy cerca de la Ciudad, y que fi el enemigo le ganaba, era grande el daño que de él podia recibir, fe fortificó con toda diligencia, ayudando al trabajo las Compañias de los otros tercios.

6 Viendo el enemigo ocupado el puefto de San Antonio, $y$ la prifa con que en él fe trabajaba, caminó la vuelta de la marina, y fe pufo en la colina del Padre Ribero, diftante de San Anroni o tiro de artilleria, que no fe pudieron en un mifmo tiempo ocupar entrambos pueftos, y afsi fe acudió á lo mas imporcante, por juzgarfe que los fuertes que habia en aquel parage podrian refiftir, ó entretencr al enemigo, hafta que llegada mayor poder, fueffe cortado; pero fucedió al contrario, pues con poca refiftencia fe rindieron á partido los fuertes de Agua de Meninos, Taparipe, y San Bartolomé, no cumpliendo el enemigo lo capirulado con ellos, haciendo mala guerra á los rendidos, con que defpertó á los demás á la debida atencion do morir antes con honra en fus pueftos, que infamemente entregandolos. Habiendo tenido noticia de efto el Gobernador, manáo prender á los Capitanes, y á uno de ellos, que era eftrangoro, fucedió, que volviendo á recogerfé á fucafa, halló la puerca cerrada , y habiendo llamado, falió á la ventana fu muger, que era Portuguefa, y natural del Brafil , y le dijo: Lue no bae bria prierta á bombre, que tan bajamente habia entregado el puefto que le eftaba encargado, $y$ que quando viniera becho pedazos, por baber fido en defenfa de la Religion Catolica, $J$ de $f u$ Rey, alegre, $y$ guftofa le recibiera. Y continuando en otras femejantes razones, corrido , y afrentado fe fue retirando á los campos, donde fiendo hallado, fue prefo, quedando contenta la Ciudad, de quo yá que tenia un hombre cobarde, fe hallaba con una muger valerofa.

7 Porque no corrieffe igual fortuna el fuerte del Rofario, le mandó el Gobernador deshacer, retirando la gente, y artilleria á la fortificacion de San Antonio, adonde el Teniente de ella, Francifco Perez de Soto, pufo dos piezas con grande trabajo, $y$. xiefgo, $y$ con otras dos que fe plantaron en San Antonio, fe coTom. $X$. 


\section{8}

\section{SITIO, Y SOCORRO}

menzó á hacer grande dańo al enemigo , y á impedir que nó continuaffe en fus fortificaciones con tanta feguridad, como lo hizo á los principios. Procuró el rebelde impedir el daño que recibia de efte puefto, $y$ viendo juntamente las grandes confequencias que fe le feguian para la expugnacion de $l_{2}$ Ciudad fi lo ganaba ; en veinte y uno de Abril, á las ocho de la noche marchó derechamente á él con mil hombres, la gente mas lucida de fu Egercito, quinientos de vanguardia, y los otros de focorro. En el camino le recibieron unas Compańias nueftras, que eftaban embofcadas, que aunque eran de muy inferior numero de gente, pelearon con tanto valor, que folos ellos hicieron re. tirar al enemigo con mucha prifa, con pérdida de dofcientos rebeldes que le degollaron, treinta prifioneros, y trefcientos heridos. Trabajabafe en todas partes por los nueftrosen las fortificaciones, habiendofe hecho las trincheras de la Ciudad en menos de quince dias, acudiendo á la obra los. Religiofos, los Clerigos, Eftudiantes, mugeres, y muchachos con grande conformidad. La obra del reducto, y trincheras, que fueron encargadas al Maefe de Campo Hector de la Calce, fe continuaban fiempre con gran cuidado, y las fortificaciones que eftaban á cargo del $\mathrm{Ca}$. piean Mayor Felipe Camaron, de cuyos pueftos fe hacia grande , y continuo dańo al enemigo. Es el Capitan Mayor Camaron, Indio de la tierra, de mucho valor, y fingular afecto al fervicio del Rey, firve con feifcientos Barbaros, y algunas ve-1 ces con mas, y es utilifsimo fu fervicio, fu refolucion, aliento, y féquito para aquel genero de guerra.

\section{A PIT ULO XXXV. PROSIGUE LO MIS MO.}

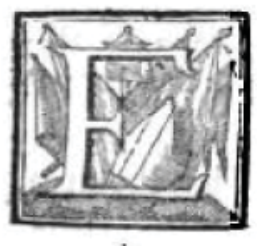

L Conde Mauricio de Nafao, viendo lo pocoque habia ganado en tanto tiempo, y quan diferente opoficion habia hallado de la que imaginó á los principios; luego que con tanta felicidad defembarcó, hizo un parlamento al Egercito, reprefentando como en apoderarfe del puerto de San Antonio confiftia la facilidad de la expugnacion de la Bahía y que ganado él, quedaba confumada la emprefa. Pufoles delante la honra, 


\section{DE FUENTE-RABIA.}

que de efto fe les feguiria, el defpojó, el faco de la Ciudad, la riqueza, y con breve trabajo acabar la guerra con felicidad, y nombre inmortal. Ponderabales el numero corto de los nueftre répecto de la gente del enemigo, los animos divididos entre sí, Naciones emulas, y difcordes, los foldados mal contentos, $\mathbf{y}$ pagados, acoftumbrados á perder, los ciudadanos fin experien cia , ni valor alguno, llenos de afombro, y confufion, viendo fobre sí un Egercito tan vietoriofo, y grande. Ofreció de parte de las Ordenes rebeldes, premios, y honras, y difpufo que novecientos foldados, de los de mas esfuerzo del Egercito, juraffen en fu mano de morir, ó ganar el puefto; y alentado con efto, efcogió mil y feifcientos de toda fu gente, y entre ellos novecientos juramentados: encargóles el afalto de las trincheras de San Antonio, y el refto del Egercito mandó que ocupaffe una colina cerca de la Cafa Quemada.

2 En efte mifmo tiempo el Gobernador Pedro de Silva , y el Conde de Bañolo, viendo que con las guerras que tenia fas Mageftad en tantas partes, podia dilatarfe el focorro que tenian pedido por diferentes avifos, pufieron fu defenfa en la milicia con que fe hallaban, que ferian dos mil y quinientos foldados, fuera de la gente de la tierra, y ciudadanos, animandolos con la defenfa de las propias cafas, mugeres, hacienda, vidas, Religion : poniendoles delante la perfidia del enemigo, fu crueldad, obftinados, y rebeldes á Dios, y á fu Rey : que eftaba librado en fu esfuerzo el vivir con honra, y libertad debajo de la mano de un Principe jufto, Catolico, y Religiofo, ó en fervidumbre durifsima en poder de hombres viles, hereges, y tiranos. Que el numero no habia que temerlo, pues efte nunca vence al valor; gente colecticia, marineros, grumetes fin honra, fin incitamento alguno de virtud, ni de honor, lo mas defpreciado, y foez de los Eftados rebeldes. Reprefentaba la valentia de las Naciones Caftellana , y Portuguefa, enfeñadas, no foloá vencer por guardar fus cafas, que los animales mas debiles faben , fuelen defender hafta la ultima defefperacion; fino á conquiftar las Naciones mas remotas, $y$ hacer formidable fu nombre en roda la circunferencia de la tierra.

3 Con eftas razones animados los foldados, defeaban llegar á las manos con el enemigo, y tuvo cumplido efecto brevemente fu defeo. Porque á los diez y ocho de Mayoá las ocho Tom. $\mathbf{X}$. Ec 2 de 
de la noche,comenzó á marchar el rebelde con los mil y feifcientos hombres, encaminado al puefto de San Antonio. Halló en elıamino algunas Compañias que eftaban embofcadas, y pelearon valerofamente, deteniendo al enemigo algun tiempo ; pero como era fuperior en gente, fue cortando la nueftra, y por medio de multitud de balas, que muy á tiempo fe jugaban de las trincheras, donde afsiftia el Maefe de Campo Don Fernando de Ludeńa, el Sargento mayor Pedro Martinez con fu tercio, y algunas Compañias del que fue de Don Bafco Mafcareñas, con refolucion, y animo grande fe arrojó el enemigo en el fofo, penfando con efto apoderarfe de las trincheras, peleando con gran + de conftancia, y levantado en el borde de ellas, y arrojado dentro de las nueftras gran cantidad de granadas, y bombas de fuego, fin perdonar arcificio ninguno de quantos podian conducir á fu intento.

4 Acudieron de focorro á toda prifa al puefto de San Antonio el Gobernador, el Conde de Bañolo, Duarte de Alburquerque, Luis Barballo, Lorenzo de Brito'Correa, el Teniente de la Artilleria Francifo Perez de Soto, y el de Maefe de Campo General Alonfo Gimenez, Martin Ferrera , y otros Capitanes, que con fu valor, y egemplo animaron á los demás foldados á rechazar al enemigo de aquel puefto; el qual viendofe muy acofado de los nueftros, queriendo esforzar, y focorrer á la gente que fe hallaba en el fofo con la que habia dejado en la colina de la Cafa Quemada, donde renia ocupado puefto para affegurar las efpaldas, é ir enviandola de refrefco á la parte que fueffe necefaria, fe le opufo el Maefe de Campo Juan Ortiz con fu tercio, y fu Sargento mayor Don Juan de Eftrada, que fe hallaban con algunas Compañias del tercio de Portugal de Pernambuco, rodo á cargo de Luis Barballo en las embofcadas prevenidas para acudir á efte intento, los quales rompieron el Eger 2 cito contrario, haciendole volver las efpaldas con gran pérdida de gente, fénalandofe en efta ocafion el Capitan Don Gregorio Cadena Vandeíra de Melo, que recibió cinco balazos, aunque ninguno de peligro , y el Capitan Don Pedro de Rojas, quedando mal herido el Capitan Antonio Rodriguez.

5 Viendo los nueftros que duraba fiempre la pelea en el fofo, fe refolvió que el Maefe de Campo Luis Barballo falieffe fuera de las trincheras á pelear con el enemigo, y defalojarle de él; 
y egecutandolo luego, faliò por el Dique de la Cafa Quemada con los Sargentos mayores Antonio de Freitas de Silva, Francifco Duarte, y otros. Dieron al enemigo de trabés, y al mifmo tiempo de frente los de las trincheras, donde fe peleó gran. de rato con fingular valor de ambas partes, hafta que el enemigo, no pudiendo refiftir, fe pufo en huída, defpues de haber peleado tres horas en el folo. Acudió con fu tercio del fitio de las Palmas á efte tiempo el Maefe de Campo Hector de la Calce, que aun tuvo lugar de dar dos cargas al enemigo al tiempo de fu retirada. Luego tocaron al arma en los fuertes de San Diego, y San Antonio, donde el rebelde con doce barcas hizo demofrracion de acometer ; y aunque á nueftra gente les pufo en algun cuidado, pero el Proveedor mayor del Eftado del Brafil Pedro Cadena de Villafanti, y Pedro Correa de Gama, que eftaban en la Plaza de Armas, con otzos Capitanes, y foldados, enviaron un recado á los Gencrales, que no tuvieffen cuidado, porque ellos focorrian aquellos pueftos, como lo hicieron con las Compańias, que eftaban de la parte de San Benito, que con gran prefteza fueron á ocupar la Playa, para impedir que el cnemigo echaffe en tierra fu gente.

6 Toda aquella noche fe afsiftió en nueftros quarteles, y luego que amaneció llegó un trompeta del Conde de Nafao á pedir fufpenfion de armas para retirar, y enterrar los muertos. Concediófele, y fue en rehenes de nueftra parte el Capitan Pedro de Arenas, quedando de la fuya otro Capitan. Entregaronfele trefcientos y veinte y fiete muertos, que el Gobernador mandó llevar en carros, demás de otros muchos que no quifieron recibir: habiendo fido los que murieron en efta noche fola feteciencos, y entre ellos ocho Capitanes, y mas de quinientos heridos. De los nueftros murieron fefenta y dos, y falieron heridos ciento y nueve, y Sebaftian de Soto, que murió dentro de pocos dias. Y los heridos particulares fueron los Capitanes Anto. nio Rodriguez, Antonio Montero Becerra, Don Juan de Tobar, Juan Perez de Melo, el Sargenro mayor $t$ Antonio Freytas de Silva, y algunos otros Alfereces, y Sargentos reformados.

7 Metió el enemigo en las trincheras, y Ciudad mas de dos mil y quatrocientas balas, fin que con ellas ofendieffe á perfona alguna, habiendo hecho grandes ruinas en cafas, $y$ ' Conventos diferentes. Fuefe continuando de nueftros pueftos la ofenfa del ene- 
enemigo, el qual para affegurarfe en la parte que fe habia retirado, hizo cuebas en la tierra , $y$ otras prevenciones, y fortifica. ciones, 2 las quales pareció al Conde de Bañolo fe dieffe un afalto real pura hacer efta faccion mas gloriofa. $Y$ habiendolo entendido el rebelde de dos prifioneros que tomó , levantó un trincheron alto para que de ninguna parte pudieffen fer viftos fus movimientos. Y fiendo la noche de veinte y feis muy tormentofa, habiendofe difparado dos piezas refolvió no decenerfe un punto, y vergonzofamente fe embarcó con tanta prifa que dejó en el quartel inuchos baftimentos, y en los fuertes de Agua de Meninos, Monferrare, y San Bartolomé, que tambien defampararon, toda la artilleria, municiones, y armas que en ellos habia. Egecutó el rebelde en quantos moradores pudo coger de aquel diftrito, notables erueldades, como to habia hecho en las fatidas, y entradas fin perdonar mugeres, viejos, y nínos, pafandolos á todos á cuchillo.

8 Cobrando nueftra gente las fortificaciones que tenia ocupadas, halló en el fuerte de Agua de Meninos una pieza de artilleria de Bronce, otra de hierro, y en cl de Monferrate cinco piezas de hierro, en el de San Bartolomé quince, y en el quartel donde fe forrificó, feis de bronce con rodos los pertrechos de guerra, fabricas del Egercito, ć inftrumentos de campaña. En veintc y fiete eltuvo el enemigo embarcado fin hacer ningun movimiento, y á la tarde envió un trompeza con un Ayudante nueftro, que tenia detenido con doce de los prifioneros que llevaba, pidiendo los fuyos. El Gobernador no losenvió, por haber hecho el Conde de Nafao mala guerra faltando á la palabra en no haber entregado los foldados del Capitan Bedoya, que tomó en el fuerte de San Bartolomé, y haber tirado con balas venenofas. En veinte y ocho por la mañana fe hizo á la vela , fin efperar que volvieffe el trompeta, con pérdida de dos mil hombres entre. muertos, prifioneros, y heridos. De nueftra parte murieron ochenta, $y$ quedaron heridos ciento y diez y feis. $Y$ habiendo llegado un navio nueftro cerca del fuerte de San Antonio, que iba de la Ciudad de Oporto, al tiempo que iba faliendo el rebelde, enviando el Gobernador doce lanchas con cinquenta mofqueteros, le trageron, y metieron en el puerto de la

Ciudad, fin que el enemigo intentaffe ofenderle. 